\title{
The influence of different spore concentrations of entomopathogenic and nematopathogenic fungi on survival of the predatory mite Amblydromalus limonicus (Garman \& McGregor)
}

\author{
Wpływ różnych koncentracji zarodników grzybów entomopatogenicznych \\ i nematopatogenicznych na przeżywalność drapieżnego roztocza \\ Amblydromalus limonicus (Garman \& McGregor)
}

Tomasz Pytlak, Żaneta Fiedler, Danuta Sosnowska

\begin{abstract}
Summary
The experiment was performed under the laboratory conditions at the Department of Biological Pest Control, Institute of Plant Protection - National Research Institute in Poznań. The aim of the study was to determine the influence of different spore concentrations of pathogenic fungi on survival of the predatory mite Amblydromalus limonicus. A. limonicus is used in greenhouse crops against larva thrips and whiteflies. Pathogenic fungi are also used in the protection of greenhouse crops. In order to conduct an effective biological protection it is necessary to know the interaction between different biological factors. Despite the lack of statistical differences in the impact of the concentration of spores of pathogenic fungi, it was noted that Beauveria bassiana and Isaria fumosorosea caused the largest mortality of $A$. limonicus. According to the proposed by IOBC (International Organisation for Biological and Integrated Control) scale all tested combinations were harmful except for Lecanicillium lecanii and Paecilomyces lilacinus applied at the concentrations of $10^{6}$ spores $/ \mathrm{ml}$.
\end{abstract}

Key words: Amblydromalus limonicus; entomopathogenic fungi; biological control

\begin{abstract}
Streszczenie
Doświadczenie wykonano w laboratorium Zakładu Biologicznych Metod Instytutu Ochrony Roślin - Państwowego Instytutu Badawczego w Poznaniu. Celem badań było określenie wpływu różnych koncentracji zarodników grzybów patogenicznych na przeżywalność drapieżnego roztocza Amblydromalus limonicus. A. limonicus jest wykorzystywany w uprawach pod osłonami w celu zwalczania larw wciornastków i mączlików. W ochronie upraw pod osłonami wykorzystuje się również grzyby pasożytnicze. Dla prowadzenia skutecznej ochrony biologicznej konieczne jest poznanie interakcji zachodzących pomiędzy różnymi czynnikami biologicznymi. Odnotowano brak statystycznych różnic dotyczących wpływu różnych koncentracji zarodników grzybów patogenicznych na przeżywalność drapieżnych roztoczy. Gatunki Beauveria bassiana i Isaria fumosorosea powodowały największą śmiertelność wśród roztoczy. Według zaproponowanej skali IOBC (International Organisation for Biological and Integrated Control) wszystkie badane gatunki grzybów były patogeniczne względem drapieżcy, z wyjątkiem grzybów Lecanicillium lecanii i Paecilomyces lilacinus w koncentracjach $10^{6}$ zarodników/ml.
\end{abstract}

Słowa kluczowe: Amblydromalus limonicus; grzyby entomopatogeniczne; ochrona biologiczna

Instytut Ochrony Roślin - Państwowy Instytut Badawczy

Zakład Metod Biologicznych

Władysława Węgorka 20, 60-318 Poznań

t.pytlak@iorpib.poznan.pl 


\section{Wstęp / Introduction}

Amblydromalus limonicus został opisany przez Garmana \& McGregora w 1956 roku. Znaleziono go na drzewach cytrusowych w Kalifornii. Jest to drapieżny roztocz, wykorzystywany w uprawach pod osłonami, głównie w celu zwalczania larw wciornastków i mączlików (van Houten i wsp. 1995). A. limonicus może również odżywiać się przędziorkami: Panonychus citri, Oligonychus punicae i Tetranychus cinnabarinus (McMurtry i Scriven 1965). Pierwsze badania z wykorzystaniem A. limonicus jako czynnika biologicznego w zwalczaniu wciornastka zachodniego Frankliniella occidentalis przeprowadzili van Houten i wsp. (1993, 1995).

W ochronie upraw pod osłonami wykorzystuje się również grzyby entomopatogeniczne, np.: Beauveria bassiana, Isaria fumosorosea, Metarhizium anisopliae, Lecanicillium muscarium oraz patogeniczny w stosunku do nicieni Paecilomyces lilacinus (EU Pesticides database). Grzyby patogeniczne wymagają wysokiej wilgotności względnej powietrza, a więc zamknięte środowisko upraw szklarniowych sprzyja ich rozwojowi (Bajan i wsp. 2012). $\mathrm{Z}$ tego powodu biopreparaty oparte na bazie grzybów patogenicznych są najczęściej wykorzystywane w tego typu uprawach. Na liście zarejestrowanych środków ochrony roślin w Unii Europejskiej znajdują się biopreparaty zawierające grzyby owadobójcze B. bassiana, L. muscarium przeciwko m.in. mączlikom i wciornastkom oraz I. fumosorosea (dawniej Paecilomyces fumosoroseus) przeciwko mączlikom (EU Pesticides database 2014). W opracowaniu optymalnych strategii, zwalczania szkodników szklarniowych, ważnym aspektem jest poznanie interakcji zachodzących pomiędzy czynnikami biologicznymi. Ma to znaczenie zarówno naukowe, praktyczne, jak i ekonomiczne.

Celem badań było określenie wpływu różnych koncentracji grzybów patogenicznych na przeżywalność drapieżnego roztocza A. limonicus.

\section{Materiały i metody / Materials and methods}

Doświadczenia wykonano w warunkach laboratoryjnych w Zakładzie Biologicznych Metod Instytutu Ochrony Roślin - Państwowego Instytutu Badawczego (IOR - PIB) w Poznaniu. Do badań wytypowano trzy gatunki grzybów owadobójczych: B. bassiana (szczep izolowany z Diabrotica virgifera - Dv-1/07), L. lecanii (szczep izolowany z jaj nicienia Heterodera schachtii pozyskanego z gleby w okolicach Torunia - Łub-05), I. fumosorosea (izolowany z gleby koło Borku w 2004 roku - Borek-04) oraz grzyba nicieniobójczego $P$. lilacinus (szczep izolowany z gleby w okolicach Torunia - Pl-2/08). Grzyby pochodziły z kolekcji Zakładu Biologicznych Metod IOR - PIB. W doświadczeniu wykorzystano zakupione w firmie dystrybucyjnej drapieżne roztocze A. limonicus. Grzyby hodowano na szalkach Petriego na pożywce PDA (Potato Dextrose Agar) $\mathrm{w}$ termostacie $\mathrm{w}$ temperaturze $25^{\circ} \mathrm{C}$ przez 14 dni. Zawiesinę wodną zarodników przygotowano w homogenizatorze zeskrobując grzybnię z 14-dniowych kultur z PDA w następujących koncentracjach (konidiów/ml): 105 $10^{6}$,
$10^{7}$. Kontrolę stanowił wariant tylko $\mathrm{z}$ wodą destylowaną. Koncentracje zarodników obliczano przy pomocy hemocytometru Goriajewa.

Na szalki Petriego wykładano bibułę filtracyjną i zwilżano w celu utrzymania odpowiedniej wilgotności. Następnie wykładano liście fasoli zasiedlone przez przędziorka chmielowca. Ogonki liści zawijano w watę nasączoną wodą w celu utrzymania jak najdłużej turgoru w liściach. Nakładano po 10 dorosłych osobników drapieżnych roztoczy A. limonicus na 1 liść fasoli. Liście z roztoczami zostały opryskane (3 rozpylenia) wodnymi zawiesinami zarodników poszczególnych gatunków grzybów patogenicznych. Szalki następnie przykryto specjalnie perforowaną folią. Tak przygotowane próby umieszczono w termostacie $\mathrm{w}$ temperaturze $26^{\circ} \mathrm{C}$ i wilgotności względnej powietrza $60 \%$. Obserwacje przeprowadzono po 5 i 7 dniach od zabiegu opryskiwania, odnotowując osobniki żywe i martwe drapieżnych roztoczy. Martwe osobniki umieszczano w komorze klimatycznej na okres 2 tygodni, w celu potwierdzenia zainfekowania przez grzyby patogeniczne. Każdy wariant wykonano w dziesięciu powtórzeniach.

Analizę statystyczną przeprowadzono za pomocą testu Fischera na poziomie istotności $\alpha=0,05$.

\section{Wyniki i dyskusja / Results and discussion}

W doświadczeniu wykazano, że koncentracje zarodników nie mają statystycznie istotnego wpływu na przeżywalność drapieżnych roztoczy $\mathrm{z}$ gatunku $A$. limonicus. Średnia liczba zainfekowanych roztoczy przez $B$. bassiana wyniosła $\geq 50 \%$. W przypadku zastosowania koncentracji $10^{5}$ i $10^{6}$ śmiertelność roztoczy wynosiła $90 \%$, podczas gdy przy koncentracji $10^{7}$ poniżej $80 \%$. Drugim najbardziej patogenicznym grzybem okazał się gatunek I. fumosorosea. Powodował on śmiertelność powyżej 90\% w każdej koncentracji. W literaturze można spotkać również informacje dotyczące patogenicznego wpływu tego gatunku grzyba owadobójczego w stosunku do roztoczy (Kim i wsp. 2008). Stosując koncentrację zarodników $10^{6}$ grzyba L. lecanii uzyskano <50\% śmiertelności, co stanowiło najniższą wartość ze wszystkich badanych gatunków. Natomiast grzyb ten zastosowany w koncentracji $10^{7}$ zarodników w $1 \mathrm{ml}$ powodował aż $100 \%$ śmiertelności drapieżcy. Podobne rezultaty otrzymał Ekbom (1979) wykazując wrażliwość pasożytniczej błonkówki Encarsia formosa (Gah.) na szczep grzyba L. lecanii. Grzyb P. lilacinus w koncentracjach $10^{6} \mathrm{za}-$ rodników powodował śmiertelność na poziomie $<75 \%$, czyli był umiarkowanie szkodliwy względem drapieżnego roztocza. Według skali toksyczności podanej przez IOBC (International Organisation for Biological and Integrated Control), gdzie śmiertelność <25\% - nieszkodliwe, 25-50\% - nieco szkodliwe, 51-75\% - umiarkowanie szkodliwe, a > 75\% - szkodliwe, badane gatunki grzybów patogenicznych $\mathrm{z}$ wyjątkiem gatunków $L$. lecanii i $P$. lilacinus zastosowanych w niższych koncentracjach były bardzo szkodliwe względem drapieżnego roztocza $A$. limonicus. Potwierdza to brak uzasadnienia w stosowaniu tych gatunków grzybów łącznie z drapieżnym roztoczem. 


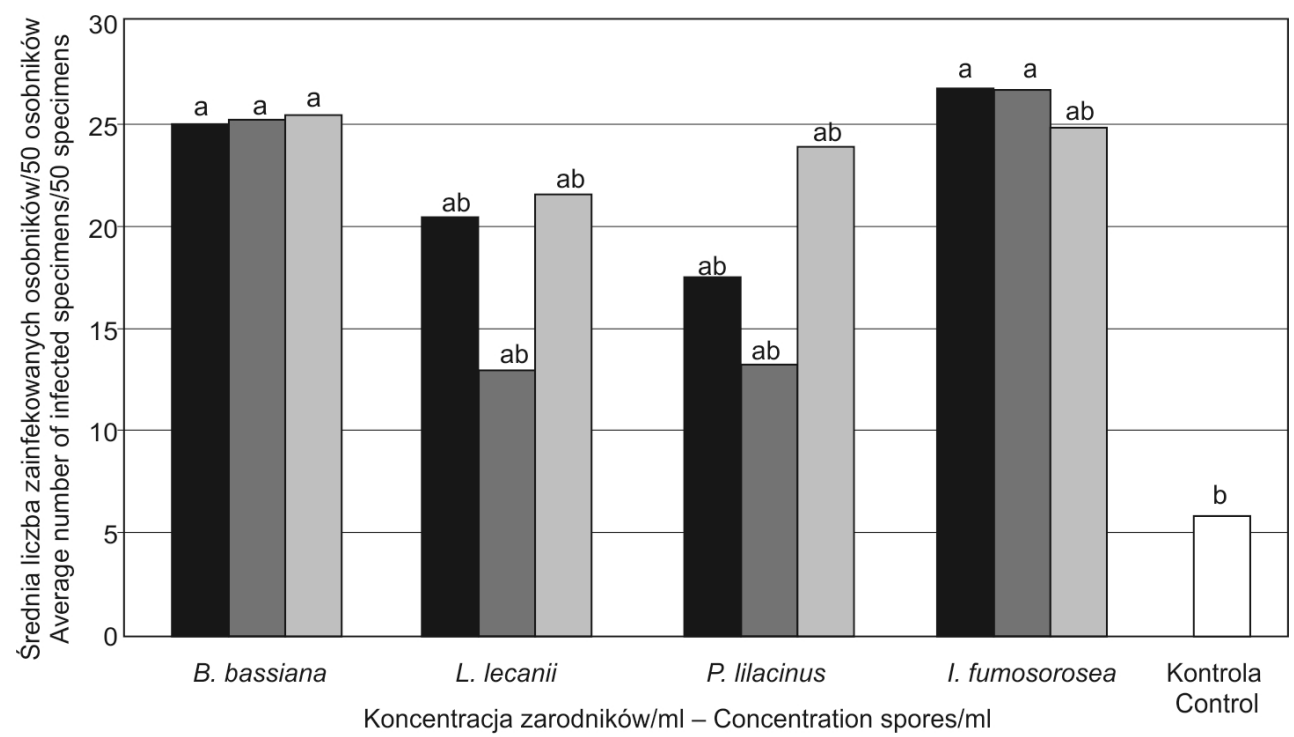

$$
\square 10^{5} \square 10^{6} \square 10^{7} \square 0
$$

Rys. 1. Wpływ różnych koncentracji zarodników grzybów entomopatogenicznych na śmiertelność drapieżnych roztoczy z gatunku A. limonicus. Średnie wartości oznaczone tymi samymi literami nie różnią się istotnie statystycznie $(\mathrm{p} \leq 0,05)$

Fig. 1. The influence of spore concentrations of the entomopathogenic fungi on mortality of the predatory mite A. limonicus. Mean values marked by the same letter are not significantly different $(\mathrm{p} \leq 0.05)$

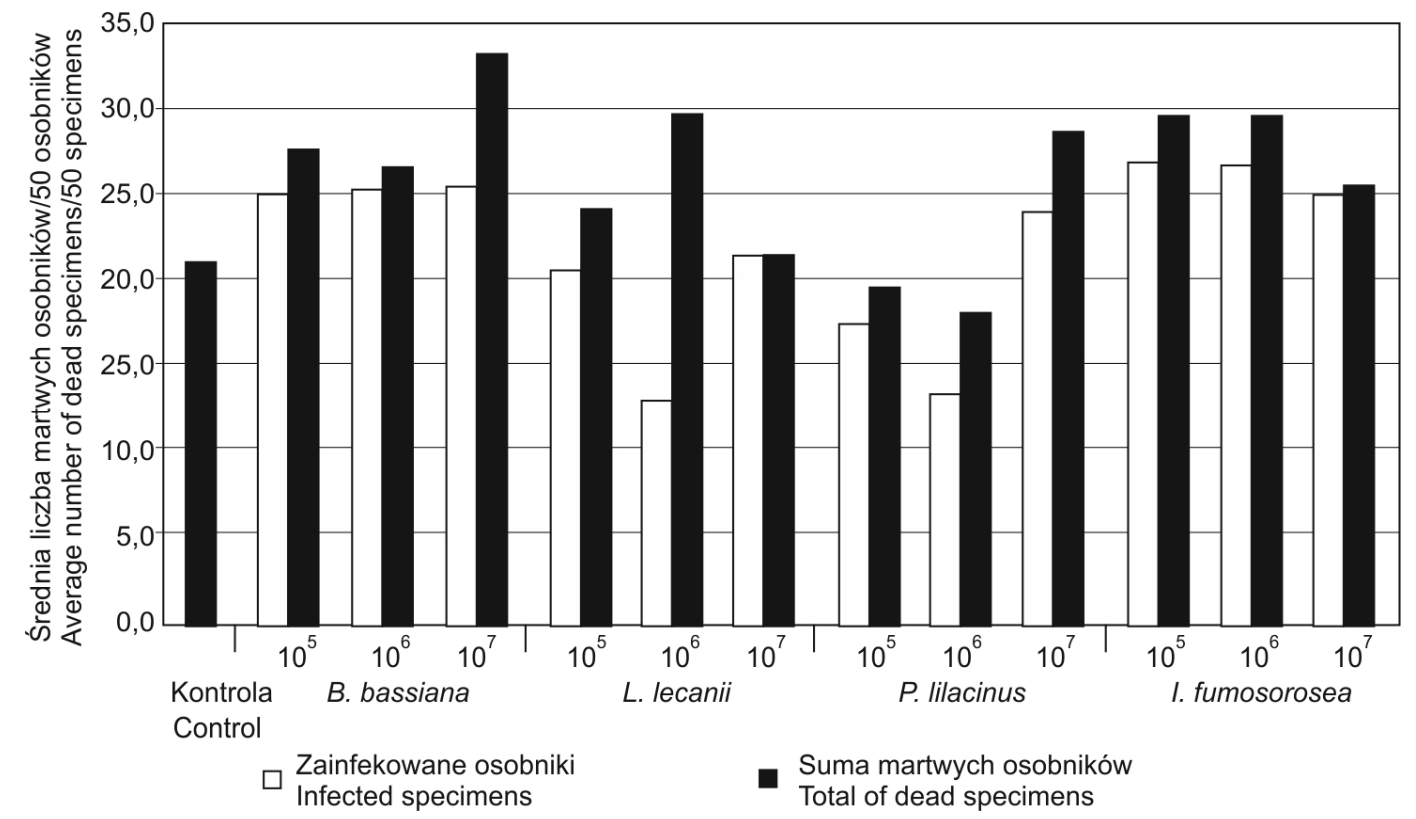

Rys. 2. Śmiertelność powodowana przez grzyby patogeniczne w stosunku do ogólnej sumy martwych osobników

Fig. 2. Mortality caused by the pathogenic fungi in relation to the total amount of dead specimens

Przy prowadzeniu integrowanej ochrony roślin możliwość wykorzystania różnych czynników biologicznych jest ważnym elementem zarówno ze względów praktycznych (szybsza i większa efektywność), jak i ekonomicznych. W literaturze znaleźć można wiele pozytywnych przykładów łącznego stosowania grzybów patogenicznych wraz $\mathrm{z}$ organizmami pożytecznymi oraz informacje dotyczące istotnego wpływu koncentracji zarodników w zawiesinie wodnej na patogeniczność grzybów owadobójczych (Jacobson i wsp. 2001; Azaizeh i wsp. 2002; Goodwin i wsp. 2002; Fiedler i Sosnowska 2008).

\section{Wnioski / Conclusions}

1. Wszystkie badane gatunki grzybów były patogeniczne względem drapieżnego roztocza $A$. limonicus.

2. Różne koncentracje grzybów patogenicznych nie miały statystycznie istotnego wpływu na przeżywalność roztoczy.

3. Najmniej patogeniczne okazały się grzyby: L. lecanii i P. lilacinus. Grzyb L. lecanii powodował śmiertelność drapieżców poniżej 50\%, co klasyfikuje go jako nisko szkodliwy względem drapieżnych roztoczy. 
4. Najbardziej patogeniczne okazały się grzyby: B. bassiana i I. fumosorosea. Grzyby te powodowały śmiertelność roztoczy w $90 \%$.

\section{Literatura / References}

Azaizeh H., Gindin G., Said O., Barash I. 2002. Biological control of the western flower thrips Frankliniella occidentalis in cucumber using the entomopathogenic fungus Metarhizium anisopliae. Phytoparasitica 30 (1): 18-24.

Bajan C., Bałazy S., Tkaczuk C. 2012. Zarys historii badań nad grzybami entomopatogenicznymi w Polsce. s. 78-91. W: „Kierunki rozwoju patologii owadów w Polsce" (I. Skrzecz, A. Sierpińska, red.). IBL, Sękocin Stary, 381 ss.

Ekbom B.S. 1979. Investigations on the potential of a parasitic fungus (Verticillium lecanii) for biological control of the greenhouse whitefly (Trialeurodes vaporarium). Swedish J. Agric. Res. $9: 129-138$.

EU Pesticides database 2014. http://ec.europa.eu/sanco_pesticides/public/?event=activesubstance.selection [Accessed: 04.04.2014].

Fiedler Ż., Sosnowska D. 2008. Wpływ różnych koncentracji zarodników grzybów owadobójczych w ograniczaniu populacji wciornastka zachodniego Frankliniella occidentalis oraz drapieżców: Amblyseius cucumeris i Orius laevigatus. [Influence of diffrent concentration of spores on effectiveness of the pathogenic fungi in reduction of western flower thrips Frankliniella occidentalis and predators: Amblyseius cucumeris, Orius laevigatus]. Prog. Plant Prot./Post. Ochr. Roślin 48 (4): 1285-1289.

Goodwin S., Steinem M., Enkegaard E. 2002. Developments in IPM for protected cropping in Australia. Bull. OILB-SROP 25 (1): $81-84$.

Jacobson R.J., Handler D., Fenlon J., Russell K.M. 2001. Compatibility of Beauveria bassiana (Balsamo) Vuillemin with Amblyseius cucumeris Oudemans (Acarina: Phytoseiidae) to control Frankliniella occidentalis Pergande (Thysanoptera: Thripidae) on cucumber plants. Biocontrol Sci. Techn. 11 (3): 391-400.

Kim J.S., Roh J.Y., Choi J.Y., Shin S.C., Jeon M.J., Je Y.H. 2008. Insecticidal activity of Paecilomyces fumosoroseus SFP-198 as a multi-targeting biological control agent against the greenhouse whitefly and the two-spotted spider mite. Int. J. Indust. Entomol. 17 (2): 181-187.

McMurtry J.A., Scriven G.T. 1965. Life-history studies of Amblyseius limonicus, with comparative observations on Amblyseius hibisci (Acarina: Phytoseiidae). Ann. Ent. Soc. America 58 (1): 106-111.

van Houten Y.M., van Rijn P.C.J., Tanigoshi L.K., van Stratum P. 1993. Potential of phytoseiid predators to control western flower thrips in greenhouse crops, in particular during the winter period. Bull. IOBC/WPRS 16 (8): 98-101.

van Houten Y.M., van Rijn P.C.J., Tanigoshi L.K., van Stratum P., Bruin J. 1995. Preselection of predatory mites to improve year-round biological control of western flower thrips in greenhouse crops. Ent. Exp. Appl. 74 (3): 225-234. 